\title{
José Luis Razo Zaragoza y los inicios de la archivística profesional en Jalisco *
}

\author{
Luis Gómez Gastélum ** \\ Cristina Ramírez Munguía *** \\ Jesús Erick González Rizo ****
}

Artículo recibido: 16 de agosto de 2013. Artículo aceptado: 18 de marzo de 2014.

\section{Resumen}

En este artículo se presenta un análisis de lo que fue el proceso de profesionalización de la archivística y los archivos en el estado de Jalisco a través de uno de sus actores. Se presenta una semblanza biográfica de José Luis Razo Zaragoza, así como de su formación profesional en archivística e historia de México. Se revisa también su vinculación con diversos archivos en el estado de Jalisco, entre los que destacan el del Instituto Jalisciense de Antropología e Historia, el Archivo His-

* El presente texto es una versión corregida y aumentada de la ponencia del mismo nombre que se presentó en las XI Jornadas Archivísticas de la Red Nacional de Archivos de Instituciones de Educación Superior, auspiciado por la Universidad Autónoma de Zacatecas en el año de 2011.

** Universidad de Guadalajara, México. gastelum@cencar.udg.mx

$\star \star \star$ Universidad de Guadalajara, México. crisol1920@gmail.com

$\star \star \star \star$ COLMICH, Centro de Estudios Arqueológicos, México. erickgrizzo@hotmail.com

INVESTIGACIÓN BIBLIOTECOLÓGICA, Vol. 28, Núm.64, septiembre/diciembre, 2014, México, ISSN: 0187-358X. pp. 173-190 
tórico de la Universidad de Guadalajara y el Archivo de Instrumentos Públicos del Estado de Jalisco. Por último, se ofrece una valoración crítica de sus aportes para la subsistencia y organización de los repositorios documentales en las instituciones mencionadas.

Palabras clave: Archivos históricos; Jalisco; Organización de archivos; Profesionalización de la archivística.

\section{Abstract}

José Luis Razo Zaragoza and the beginnings of the archival profession in Jalisco

Luis Gómez-Gastélum, Cristina Ramírez-Munguía and Jesús-Erick González-Rizo

Focusing on an important early figure, this article examines the process of professionalization of the archival and record-keeping fields in the Mexican state of Jalisco. A biographical sketch of José Luis Razo Zaragoza, including a description of his vocational training in historical archives of Mexico, is presented. The paper also reviews his association with several archives in the State of Jalisco, including Jalisco Institute of Anthropology and History, the Historical Archive of the University of Guadalajara and the Archive of Public Documents of the State of Jalisco. Finally, the researcher offers a critical assessment of his contribution to the organization and continuance document repositories at these institutions.

Keywords: Historical Archives; Jalisco; Archive Organization; Professionalization of the Archival Science.

\section{INTRODUCCIÓN}

1 texto que se presenta aquí es un derivado del proyecto de investigación ¿ El papel del Instituto Jalisciense de Antropología e Historia en la investigación arqueológica del Occidente de México. Historia de la arqueología en Jalisco". Éste tiene como objetivo general analizar la forma en que se dio la 
investigación arqueológica en el estado de Jalisco entre 1959 y 1976, fecha en que se consolida la presencia del Instituto Nacional de Antropología e Historia (INAH) en la entidad. Busca también contextualizar a los actores e instituciones vinculados a esta actividad en el periodo mencionado. Para lograrlo, su metodología principal está dada por la investigación documental en archivos y la bibliográfica en bibliotecas, además de la entrevista etnográfica y las visitas en campo a sitios arqueológicos. En cuanto a los archivos, se han consultado hasta este momento los acervos documentales del Instituto Jalisciense de Antropología e Historia (IJAH), del Consejo de Arqueología del INAH, del Archivo Histórico de la Universidad de Guadalajara, del Archivo Histórico de Jalisco y del Archivo de Instrumentos Públicos del Estado de Jalisco, aún cuando no en todos se ha encontrado información o se ha podido tener acceso a datos relevantes para nuestro trabajo. Si bien los principales resultados obtenidos hasta ahora son de interés para los procesos de institucionalización de la arqueología en Jalisco, la documentación encontrada y consultada nos ha permitido vislumbrar otra clase de procesos colaterales a nuestro objeto central de estudio. Éste es el caso que hoy nos ocupa, donde el personaje central es un académico y funcionario público vinculado con la investigación histórica y los archivos del mismo tipo. Su actividad profesional se desarrolló entre las décadas de 1940 y 1990 y tuvo impacto en las áreas de archivonomía, biblioteconomía, historia y arqueología. En las líneas siguientes buscaremos ofrecer un panorama de su actuar, contextualizándolo en su tiempo y con las instituciones que le tocó vivir, para explicar cuáles fueron sus aportaciones en el desarrollo profesional de los archivos de Jalisco.

\section{José Luis Razo Zaragoza y Cortés}

\section{Semblanza biográfica}

José Luis Razo Zaragoza y Cortés nació en La Barca, Jalisco, el 23 de septiembre de 1917 (Figura 1). Vivió en dicha población hasta el año de 1935 y durante ese tiempo realizó la primaria, además de aprender el oficio de carpintero-ebanistero. Para continuar su instrucción formal su familia se mudó a la capital del estado y allí tuvo la oportunidad de realizar los estudios de secundaria, preparatoria y licenciatura. Obtuvo el título de abogado en la Universidad de Guadalajara (U. de G.) en noviembre de 1949. Vale la pena resaltar que su tesis profesional mostraba desde entonces un interés en cuanto a las cosas propias de la tierra. A partir de ese momento, su vida profesional se dividió entre archivos, bibliotecas y lo que sería su actividad principal, 
el servicio desde el IJAH en las labores de tipo histórico y antropológico que la ley le atribuyó a dicha institución (Topete y Pedraza, 2007).

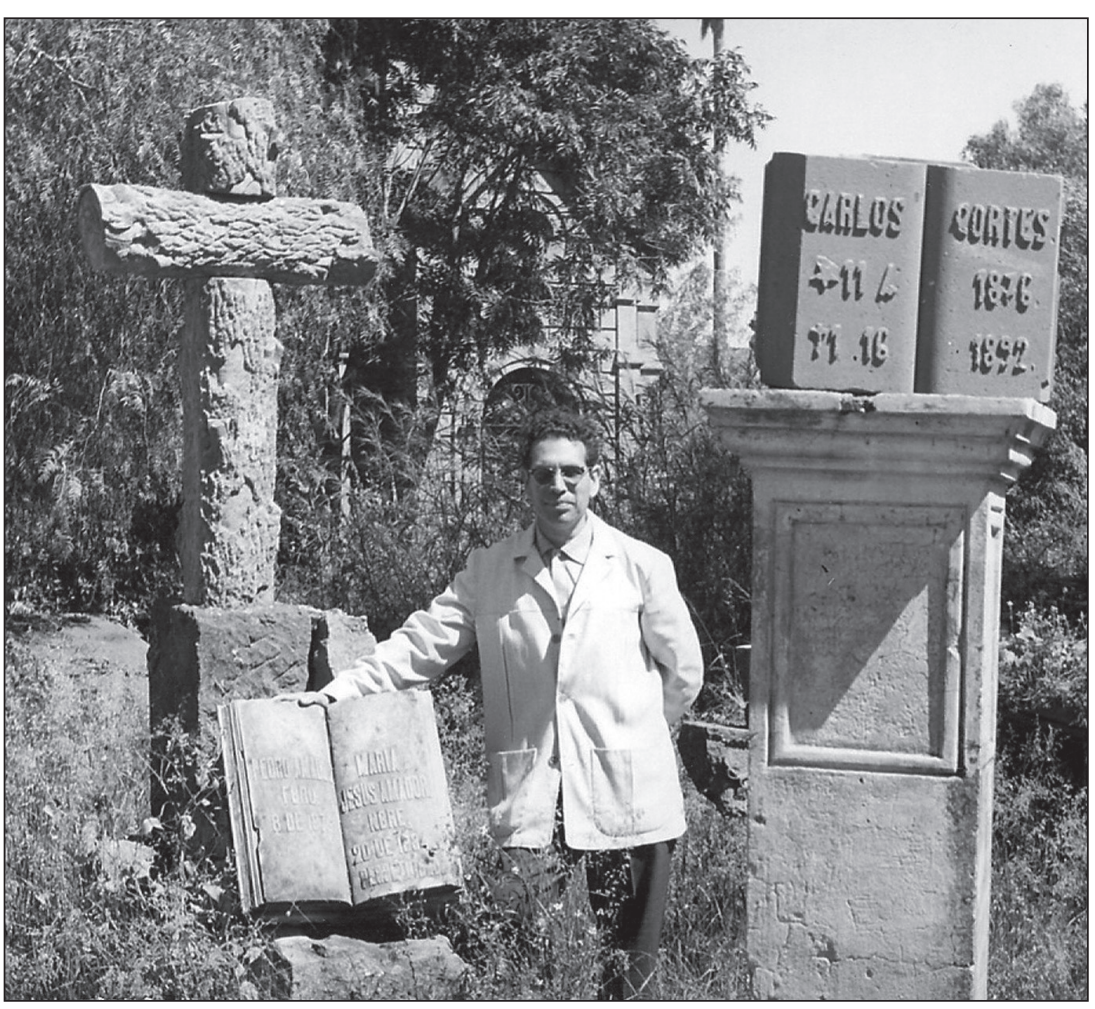

Figura 1.

En su preparación profesional destaca el hecho de que, para una época en donde el título de abogado bastaba para tener una actividad laboral larga y exitosa, él decidió realizar estudios de posgrado en la ciudad de México. En el nivel de maestría fue alumno en la Escuela Nacional de Antropología e Historia (ENAH) y en la Universidad Nacional Autónoma de México (UNAM) entre 1950 y 1954. De acuerdo con un certificado de estudios expedido por la ENAH en enero de 1955, tenía debidamente acreditados los estudios de Maestro en Historia, especializado en Historia de México, Maestro en Biblioteconomía y Maestro Archivista Paleógrafo. Cabe señalar que para el periodo de 1950 a 1952 recibió beca de la U. de G. a fin de hacer estudios para el manejo de archivos históricos, por un monto de 300 pesos mensuales más ayuda para transporte. Según se establece en su propio currículum, las tesis para obtener los grados respectivos estuvieron listas en 1957. La que le 
permitió conseguir el grado de Maestro en Historia se tituló Fundaciones coloniales en el Nuevo Reino de Galicia, mientras que la escrita para los grados de Maestro Archivista Paleógrafo y Maestro en Biblioteconomía se intituló Proyecto para la Catalogación y Clasificación del Archivo Municipal de Guadalajara y su Acervo Bibliográfico, y se constituyó en la primera aportación profesional del autor en el campo de la archivística (Razo Zaragoza, 1991a).

En cuanto a su vida laboral, Razo estuvo fuertemente vinculado a los archivos y las bibliotecas. Su primer empleo lo obtuvo en la Biblioteca Pública del estado de Jalisco, cuando fue nombrado Oficial de Catalogación en el año de 1944. Posteriormente, en la misma biblioteca, se le otorgó el nombramiento de Oficial de Tercera en 1947. En el año de 1953 el Ayuntamiento de Guadalajara lo nombró Jefe de la Sección de Archivos, en donde además de cuidar el correcto funcionamiento de la dependencia logró reanudar la publicación de la Gaceta Municipal. En 1955, la U. de G. lo nombra Director del Archivo de Investigaciones Sociales, dependiente del Instituto de Bibliotecas. Para 1957 tuvo tres cargos relacionados con las bibliotecas, el primero como asesor técnico de la Biblioteca Central del Seguro Social, el segundo para la organización y catalogación de la Biblioteca "Mariano de la Bárcena" de la Dirección General de Geografía y Meteorología de la Secretaría de Agricultura y Ganadería, y el tercero como Secretario del Departamento de Archivos Históricos y Bibliotecas del INAH. Desde 1958 ejerció la docencia en la Facultad de Filosofía y Letras de la U. de G., lo que hizo hasta el año de 1987. En 1959 recibirá el cargo de Secretario del IJAH, el cual tendrá hasta 1983, cuando lo nombran Director del mismo y que conservó hasta el año 2000. Como cronista recibió dos nombramientos, uno en el municipio de La Barca, Jalisco, en 1962 y otro en Guadalajara en 1968. Ese mismo año fue designado Paleógrafo del Archivo de Instrumentos Públicos del estado de Jalisco (AIPEJ), mismo que ejerció hasta la década de 1990. Además de lo anterior formó parte de innumerables comisiones universitarias y gubernamentales, principalmente a nivel municipal y estatal, siempre en relación con las disciplinas histórica y antropológica (Razo Zaragoza, 1991a; Topete y Pedraza, 2007).

\section{Formación profesional}

Como se señaló en el apartado anterior, nuestro personaje fue un caso de excepción en la formación académica en su tiempo. Con una base de estudios en Derecho, decidió orientarse a las cuestiones históricas y lo hizo desde su materia prima: los documentos de archivo. Para lograr un buen manejo de la investigación histórica, todo historiador debe tener un amplio conocimiento de los archivos que resguardan los documentos generados en la época que le 
interese estudiar. Sin embargo, en ese tiempo pocos eran los archivos organizados, más bien se trataba de bodegas de papeles viejos, sin orden y en ocasiones descuidados o, peor aún, menospreciados. Para entrar en ellos había que tener mucho valor, pues el tamaño de la empresa para obtener cualquier información bien podía ser superior a las fuerzas de cualquier persona.

En ese sentido, para acometer la tarea y hacerla de modo que resultara útil al público interesado, había que prepararse de la mejor manera. Razo Zaragoza lo hizo estudiando para volverse un profesional de la archivística. Señalamos ya que entre 1950 y 1952 hizo los estudios correspondientes en la ENAH, siendo sus materias específicas las siguientes: Clasificación y Catalogación I y II, Técnica de Conservación y Reparación de Documentos I y II, Paleografía I, II y III, Ubicación y Clasificación de las Fuentes Documentales Manuscritas en México I y II y Organización de Archivos. Los cursos restantes abordan la historia y la historiografía antigua y colonial de México y de América. Como puede apreciarse, el sustento para la formación como archivista hace énfasis en los documentos, su cuidado, organización y ubicación. Además este plan de estudios está claramente orientado hacia los archivos históricos, así lo demuestra el curso sobre documentos manuscritos en conjunto con aquellos que abordan las diversas épocas de la historia mexicana y, en particular, las clases sobre paleografía (Razo Zaragoza, 1991a).

No conforme con lo anterior, y consciente de que para la comprensión cabal de un documento debe analizarse su contexto histórico, efectuó también la Maestría en Historia, especializada en Historia de México, y la Maestría en Biblioteconomía. En éstas encontramos materias que son complementarias en el aspecto técnico de la archivística, como Técnicas Fotográficas y Audiovisuales, Bibliografía, Administración y Organización de Bibliotecas, así como Historia del Libro y de las Bibliotecas. De nueva cuenta, el resto de los cursos hacen referencia a aspectos teóricos y descriptivos de la disciplina histórica. Ahora bien, aun cuando en la información proporcionada por el propio profesional se señalan tres maestrías distintas, José Adolfo Rodríguez Gallardo (2003) menciona que tanto la etiqueta de archivista paleógrafo como la de biblioteconomía correspondían a especializaciones al interior de la Maestría en Historia que ofrecía la UNAM. Si esto fuera así, entonces Razo Zaragoza logró la Maestría en Historia con tres especializaciones: historia de México, archivista paleógrafo y biblioteconomía.

Visto a la distancia, consideramos que esta formación lo capacitó para efectuar una labor integral en el campo de los archivos y las bibliotecas. Del análisis de los planes de estudio de sus posgrados se desprende que tenía la formación suficiente para manejar dichas instituciones en sus aspectos técnicos, y para obtener y ofrecer información como archivista y además como 
investigador, además de proponer mejoras para el manejo de ambos establecimientos. Adicionalmente, como abogado, poseía el suficiente conocimiento jurídico como para identificar los alcances legales que tiene el manejo de cierta información de archivo, aun cuando ésta se encontrara ya en un archivo histórico.

\section{Actuación profesional}

Ya se ha mencionado que los archivos fueron parte fundamental en su vida profesional. El primer cargo que tuvo con poder de decisión fue la jefatura del Archivo Municipal de Guadalajara en 1953. Para la época el archivo ocupaba el sótano del Palacio Municipal, prácticamente sin organización alguna. Desafortunadamente para nosotros, en los acervos visitados no se ha encontrado documentación específica en torno a su labor en esta dependencia. Sin embargo, por las gacetas municipales publicadas bajo su dirección podemos saber que, al menos durante los años de 1954 y 1955, el archivo tuvo un presupuesto de egresos propio y su personal estaba encuadrado bajo un organigrama. Éste estaba compuesto por un jefe, un subjefe, dos archivistas, un cronista, un mecanógrafo y un mozo. Dado que la responsabilidad de la dependencia recae en su titular, no sería extraño que esta organización y la obtención de presupuesto propio se debieran a su propia actuación (Matute Remus, 1954: 25; Ayuntamiento de Guadalajara, 1955: 42). Además, llama la atención que, cuando en otros lugares de la República las autoridades ni siquiera contemplaban los archivos, la administración municipal tapatía encabezada por Jorge Matute Remus hiciera mención explícita de la importancia del archivo como depositario de documentos de interés histórico. Al mismo tiempo, indicaba que "los expedientes y documentos se clasifican y catalogan conforme a los adelantos técnicos en esta materia" (Matute Remus, 1954:5).

Por otro lado, de su paso como director del Archivo de Investigaciones Sociales del Instituto de Bibliotecas de la U. de G., no hemos encontrado documentación que haga referencia a dicha actividad. Mismo caso es el de su nombramiento como Secretario del Departamento de Archivos Históricos y Bibliotecas del INAH. Sin embargo, al analizar su currículum, es posible que esto se deba a que fue corto el tiempo en que se desempeñó en cada uno de estos cargos.

Como se mencionó, en 1962 recibió el nombramiento de cronista de La Barca, Jalisco, y parte de sus funciones fue encargarse de un archivo histórico. De acuerdo con su propia información, integró un acervo con materiales que él mismo donara al municipio y que fueron organizados y expuestos al público a manera de museo, sin dejar de ofrecer el servicio de archivo propia- 
mente dicho. Para ello fueron habilitadas las salas del lado poniente del museo "La Moreña", en la primera de las cuales se organizaron 17 secciones que abarcaron los siguientes temas: 1. Época prehistórica, 2. Época precolombina, 3. Descubrimiento y población del valle, 4. Los albores de la ciudad, 5. Época virreinal, 6. La Barca en la Guerra de Independencia, 7. La ciudad en la consumación de la Independencia, 8. Primeros gobiernos de Jalisco, 9. La Barca en el Imperio de Iturbide, 10. El Imperio de Maximiliano, 11. Época juarista, 12. La Barca en tiempos de Don Porfirio, 13. La Barca dentro de la Revolución, 14. La Cristiada, 15. Época contemporánea, 16. Gobernantes barcenses, 17. Monedas de circulación en La Barca (Razo Zaragoza, 1991b).

La segunda sala ofreció información principalmente de carácter visual, integrada por 16 secciones: 1. Cartografía, 2. Epigrafía de la ciudad, 3. Periodistas y periódicos locales, 4. Músicos, compositores e intérpretes, 5. Testimonios de la educación media y superior en La Barca, 6. Mosaico gráfico de La Barca, 7. Barcenses y moradores distinguidos, 8. Retratos de coterráneos esclarecidos, 9. La Barca en la poesía, 10. Graficas antiguas de la ciudad, 11. Parroquia de Santa Mónica, 12. Bibliografía Barcense, 13. El río Lerma, desgracias y beneficios, 14. Don Francisco Velarde en la historia, 15. Última remodelación de la Iglesia Parroquial de Santa Mónica, 1939, 16. Gloria Nacional (Razo Zaragoza, 1991b).

En la organización anterior es clara la intención didáctica, muy probablemente dirigida a la población de dicha cabecera municipal y sus alrededores. Todavía hoy es muy escaso el número de investigadores que se han preocupado por abordar dicha región, por lo cual resulta lógico que no se haya organizado pensando en éstos en primera instancia. Sin embargo, la organización por periodos cronológicos sienta las bases para una posterior ordenación que observe los cánones establecidos por la archivonomía para aquellos de carácter histórico, como se verá más adelante. Por ello, es rescatable su interés por difundir primeramente entre sus coterráneos y visitantes interesados los documentos propios de la historia regional.

La relación de Razo Zaragoza con el AIPEJ fue larga y fructífera. El nombramiento recibido allí fue el de paleógrafo del mismo, según copia del oficio en el que se le comunica la designación, desde el 1 de marzo de 1968, aun cuando el propio interesado refiere que lo fue desde el año de 1964 (Razo Zaragoza, 1991a: 15). En este puesto sucedió a Luis Páez Brotchie, quien también se dedicó a la investigación histórica, pero, a diferencia de aquél, lo hizo con una formación autodidacta (Gobierno de Jalisco, 2011). En la actualidad, el AIPEJ es la dependencia de la Secretaría General de Gobierno destinada "a preservar la prestación de servicios producto de la actuación notarial, a falta del titular de la función o imposibilidad legal del mismo, así como 
ejercer las atribuciones que en materia de control de la actuación notarial le confiere la Ley del Notariado para el Estado" (Torres Verdín, 1990: s. pág.). Este mismo autor señala que el acervo de su sección histórica se divide en tres grandes áreas: libros de tierras y aguas, libros de Gobierno de la Audiencia de Guadalajara y la Escribanía. Entre estos documentos nuestro personaje laboró de manera cotidiana, consagrándose a dos actividades principales: la elaboración de índices de los contenidos del archivo y la paleografía de los documentos solicitados por el público. En cuanto a la primera, son de su autoría el Índice de los Libros del Ramo de Tierras y Aguas, así como el Índice de los Libros de Gobierno de la Audiencia del Nuevo Reino de Galicia, en lo relativo al ramo ya señalado (Razo Zaragoza, 2004). Sobre la segunda, hizo la paleografía de innumerables títulos virreinales de propiedad comunal, además de distintas mercedes reales otorgadas a particulares de los reinos de Nueva Galicia, Nueva Vizcaya y otras zonas de la Nueva España (Razo Zaragoza, 1991a).

La relevancia de ambas tareas es de suyo evidente, cuando todavía a fines del siglo XX, durante el año de 1989, se hablaba de elaborar índices de los libros de gobierno en el archivo señalado (Susana Pacheco, comunicación personal), por lo que su confección entre las décadas de 1960 y 1970 sin el auxilio de las tecnologías de la información y la comunicación, que empezaban a surgir en ese momento, constituía una labor lenta y dedicada cuyos frutos no alcanzarían a verse sino muchos años después. Además, aun cuando en ciertos círculos académicos estas tareas se menosprecian (González, Dorantes y Olveda, 1975; Muriá, 1989), debe reconocerse que el primer paso para controlar cualquier acervo es saber con qué tipo y cantidad de documentos se cuenta. Para ello los índices son herramientas indispensables.

En cuanto a la paleografía, en principio los trabajos efectuados en el AIPEJ debieron haberse desprendido de la elaboración de índices, ya cuando el documento estaba identificado y localizado. No sabemos si con anterioridad a Razo Zaragoza existieron registros en este repositorio, aunque probablemente así debió haber sido a juzgar por las contribuciones de Páez Brotchie (Gobierno de Jalisco, 2011). Independientemente de ello, la labor paleográfica de Razo Zaragoza trascendió los límites del AIPEJ, pues con la capacitación recibida en la ENAH y la UNAM, aunada a su práctica en dicho archivo, en el IJAH y en la docencia que ejerció en la Facultad de Filosofía y Letras de la U. de G., realizó una serie de trabajos sobre documentos fundamentales para la historia colonial del occidente de México, algunos de los cuales fueron publicados mientras que otros aún están inéditos. Destacan aquí la Crónica Miscelánea de la Sancta Provincia de Xalisco, además de las Actas de Cabildos de la Ciudad de Guadalajara. En ambos casos las ediciones efectua- 
das por el IJAH cuentan, en sus estudios introductorios, con las normas y reglas que utilizó para llevar a cabo la paleografía (Razo Zaragoza, 1968; 1970).

En 1959 nuestro personaje recibió un nombramiento que lo vincularía a una institución de por vida. Por acuerdo del Gobernador del estado de Jalisco y del Director General del INAH es designado Secretario del IJAH. En esta dependencia daría los mejores frutos de su vida profesional. En virtud de que en la ley que lo creó el IJAH fue establecido como "dependiente del INAH en los aspectos técnicos” (Galván Ruiz, 1988: 180), se convirtió en un organismo coadyuvante en la vigilancia y protección del patrimonio arqueológico e histórico del estado de Jalisco. Con este mandato el personal del Instituto recorrió la entidad para localizar sitios arqueológicos, conocer de saqueos y del tráfico de piezas prehispánicas, así como denunciar afectaciones para que la autoridad federal interviniera en la exploración y restauración de estos monumentos.

Todas estas acciones fueron registradas en el archivo de la institución. Como Secretario, estaba facultado legalmente para su manejo. Si a ello agregamos su preparación profesional en la materia, tendremos como resultado la organización del acervo documental producto de la actividad efectuada por el IJAH. Actualmente, éste se encuentra establecido con un criterio administrativo en el que se combina un orden alfanumérico. Por las propias características del instituto, debemos señalar que se trata de un acervo temático, pues cubre principalmente sólo una de las acciones que debería garantizar el Estado a sus ciudadanos, considerada en ocasiones como de las menos importantes; es decir, el acceso a la cultura (Gómez, Ramírez y Guzmán, 2009).

Como es sabido, a principios de la década de 1970 el estado de Jalisco no contaba aún con un archivo histórico. En esas fechas Razo Zaragoza se encontraba muy activo preparando una propuesta para la creación de dicha institución, buscando que quedara bajo el auspicio de la U. de G. Ésta fue hecha del conocimiento de su Rector, Rafael García de Quevedo, en escrito de fecha 30 de junio de 1973. En éste se hace mención de una conversación previa en la cual se manifestó "la conveniencia de establecer el Archivo Histórico de Jalisco dependiente de la Universidad de Guadalajara" (AIJAH, fondo Razo Zaragoza, caja 12, carpeta 38), a la vez que se solicita el apoyo institucional señalándose que su fundación implicaría "indiscutiblemente sentar un precedente de lo que una Institución que pugna por las actividades intelectuales puede hacer si se cuenta con la anuencia de las autoridades de la misma" (AIJAH, fondo Razo Zaragoza, caja 12, carpeta 38). Desafortunadamente, la idea no prosperó y no conocemos las razones de ello. Sin embargo, con el tiempo el proyecto se volvería público pues en diciembre de 1981, en un artículo intitulado "Archivo Histórico de la Universidad de Guadalajara. Un estudio. Un 
proyecto. Una realidad”, presentó al público lector de la revista Eco del IJAH su propuesta para la creación de un gran archivo histórico. Éste resguardaría los documentos que diversas instituciones civiles y religiosas del occidente de México expidieron desde la era virreinal hasta la revolucionaria.

En dicho trabajo enumeró las distintas instituciones que albergan -o dejaron- en sus acervos material documental digno de ser preservado, tales como los ayuntamientos (en especial el de Guadalajara), la Real Audiencia, las Alcaldías Mayores y Corregimientos, los Presidios, la Real Hacienda, el Real Patronato, la Real y Literaria Universidad de Guadalajara, el Archivo de Instrumentos Públicos, el Archivo de Catedral, los archivos parroquiales, la Intendencia de Guadalajara y, finalmente, el estado de Jalisco (Razo Zaragoza, 1981).

El autor sugiere la creación de un archivo documental principalmente enfocado a la época colonial, y señala que:

Esta nueva Institución podría denominarse ARCHIVO HISTÓRICO DE LA UNIVERSIDAD DE GUADALAJARA, y para formar su acervo documental recurriría a todas aquellas Instituciones neogallegas y contemporáneas que poseen tan valioso tesoro [...] Sin embargo, de tantos materiales como han legado dichas dependencias, el ARCHIVO HISTÓRICO de la Universidad de Guadalajara tan sólo trataría de reunir los más, y estos serían: el de la Real Audiencia, el del Real Consulado, el de los Reales Estancos, el de la Real Hacienda, el de la Real y Literaria Universidad de Guadalajara, el del Supremo Tribunal de Justicia, el de los Centros Conventuales, el del Clero Regular y Secular, el de los Bienes de Difuntos, y el de todos aquellos que a lo largo de la organización de éste Archivo Histórico, se vayan considerando pertinentes, independientemente de que se encuentren en el país o en el Extranjero. (Razo Zaragoza, 1981: 18. Mayúsculas en el original)

Sobre el acervo, se resalta que debe integrarse con documentos originales, pero en los casos en que no fuera posible obtenerlos se recurriría a copias fotostáticas, xerográficas y microfilms. Además, abogaba por la construcción de instalaciones modernas y adecuadas para su resguardo, que permitieran preservar correctamente los documentos (Razo Zaragoza, 1981: 18). Para su catalogación y organización expone un ordenamiento por ramos, entre los que se incluyen alcabalas, alhóndigas, administración de rentas, bienes de difuntos, criminal, hospitales, indios, inquisición, mercados, panteones, universidad y muchos más.

Para volver operativa la dependencia, el autor señalaba que sería necesaria la creación de un Departamento de Estudios Históricos, anexo y dependiente del archivo, que aprovechando a los egresados de la Facultad de Filosofía y Letras se encargaría del análisis de los documentos para elaborar y publicar trabajos relativos a la historia jalisciense. Además, deberían orga- 
nizarse otros dos departamentos, uno de Catalogación y Clasificación y otro de Restauración y Conservación (Razo Zaragoza, 1981: 18).

A diferencia de lo anterior, que quedó en propuesta, existe un archivo que fue ordenado por el propio Razo Zaragoza y que se conserva hasta la actualidad. Se trata en sentido estricto de un archivo personal que, según Topete y Pedraza, es "el acervo del polígrafo [sic], historiador, docente y cronista José Luis Razo Zaragoza” (2007: 9). Éste fue adquirido en comodato por la Secretaría de Cultura de Jalisco y constituye el denominado "Fondo Razo Zaragoza" que se encuentra depositado en el Centro Cultural "La Moreña", ubicado en La Barca, Jalisco. Cabe señalar que, al momento de la adquisición del mismo, "los documentos ya contaban con número de inventario y estaban divididos en secciones: cartas y escritos, bibliografía, fotografías, hemeroteca, mapas y croquis; debido a esto y para no alterar o confundir la numeración se respetaron los parámetros ya existentes" (Topete y Pedraza, 2007: 11). A partir de la información proporcionada por estas autoras y observando el contexto que rodea a este fondo, se puede considerar que se trata de una buena muestra del tratamiento que daba Razo Zaragoza a los archivos.

\section{Actuación docente}

Como se mencionó con anterioridad, una de las áreas fuertemente atendida por nuestro personaje fue la docencia. La ejerció tanto a nivel bachillerato como a nivel licenciatura, y es esta última la que nos interesa. Prácticamente desde la creación de la Facultad de Filosofía y Letras de la U. de G., Razo se incorporó a su personal docente en la Licenciatura en Historia. Allí se encargó de cursos como Historia de Jalisco y Paleografía, además de ofrecer materias relacionadas con la organización de bibliotecas y archivos. De hecho impulsó la creación de la Licenciatura en Biblioteconomía en la propia facultad, aunque tuvo una vida efímera.

Vale destacar el hecho de que durante la década de 1960 fueron sus alumnos una serie de jóvenes que posteriormente encabezarían el rescate integral de la historia jalisciense, entendiéndose por ello el rescate de la documentación, el establecimiento de archivos y la investigación y redacción de textos históricos. Se hace referencia aquí a personalidades tales como Carmen Castañeda, José María Muriá, Jaime Olveda, Helen Ladrón de Guevara, entre otros que durante la década de 1970 serían actores fundamentales en el establecimiento de dependencias como el Archivo Histórico de Jalisco y el Centro Regional de Occidente del INAH, instancias desde las cuales se evaluó el estado de la documentación histórica y sus repositorios, se detectaron problemas para su resguardo y conservación, y se emprendieron acciones para resolverlos y 
asegurar la permanencia de los testimonios históricos (González, Dorantes y Olveda, 1975; Fernández, 2008). Si bien ninguno de los mencionados académicos ha dicho que su fuente de inspiración para lo que hicieron fuera Razo Zaragoza, e incluso algunos han criticado velada o abiertamente su producción historiográfica (Olveda, 2008: 16-17), es innegable que fueron sus alumnos, conocieron sus ideas y deben parte de su formación inicial como profesionales al maestro Razo Zaragoza. De esta manera, nuestro personaje aportó su "grano de arena" para el establecimiento de instituciones archivísticas en Jalisco.

\section{Conclusiones}

La valoración del vínculo que tuvo Razo Zaragoza con los archivos puede hacerse desde diversas ópticas. Sin embargo, es de principal importancia contrastar su actuar con dos aspectos. El primero, el estado que guardaba la archivística profesional en su aspecto teórico; el segundo, los avances que la disciplina tenía a nivel nacional, principalmente en lo relativo a su quehacer empírico. En torno a la primera cuestión no hay que olvidar que la archivística se consolidó como disciplina por propio derecho en el siglo XX y que el área geográfica donde tuvo mayor desarrollo fue Europa. Allí se establecieron las bases teóricas y metodológicas que guían el actuar de los archivistas. Según Montilla y Mena (2013), los autores más prestigiosos en este aspecto fueron los holandeses Samuel Müller, Johan Feith y Robert Fruin, el británico Charles Hilary Jenkinson y el italiano Eugenio Casanova, mismos que influyeron al mundo entero con sus reflexiones. De acuerdo con sus teóricos e historiadores, en la primera mitad del siglo pasado dominó la archivística clásica, también conocida como estatista, histórico-tecnicista o como desarrollo historiográfico y teoría especulativa (Giraldo Lopera, 2009; Montilla y Mena, 2013; Vivas Moreno, 2004). De acuerdo con Vivas Moreno (2004), en este periodo la archivística se consideró como una disciplina historiográfica, ubicándola de hecho como una de las ciencias auxiliares de la historia. Además, tuvo un fuerte desarrollo teórico al aparecer en ese momento el denominado Principio de procedencia, mismo que garantiza "[...] por un lado, que los documentos provenientes de una procedencia deben estar reunidos y sin mezclarse con los de otra procedencia, y por otro, que dichos documentos deben mantenerse ordenados naturalmente, esto es, respetando la funcionalidad y organización institucional" (Vivas Moreno, 2004: 86). También se desarrolló la descripción, al tiempo que se elaboraron instrumentos heurísticos, tan es así que se indica: "Es, pues, el momento de los catálogos sistemáticos, de los índices y guías, de las recopila- 
ciones documentales, de las colecciones diplomáticas" (Vivas Moreno, 2004: 86). Como parte de la consolidación disciplinar se crean centros de enseñanza archivística, además de darse un auge en la legislación en la materia. Todo ello sentará las bases para el surgimiento de la archivística moderna y el desarrollo de los archivos administrativos. Visto en conjunto, indican Montilla y Mena, en ese momento se dieron las condiciones para que la archivística europea "[...] se centrara exclusivamente en ofrecer un conjunto de técnicas que garantizaran el acceso y uso de documentos antiguos y medievales a los historiadores" (2013:49).

Ahora bien, México no ha sido una nación en la que la teoría y la metodología de la archivística hayan tenido un desarrollo independiente. Más bien aquí se han aplicado los principios formulados en otras latitudes. En ese sentido, de acuerdo con lo expresado por Ramírez Aceves et al. (2011), la archivística en nuestro país durante el siglo XX puede encuadrarse en lo expresado en el párrafo anterior. La existencia del Archivo General de la Nación (AGN), la legislación que lo rigió en el periodo de interés así como la existencia de centros de enseñanza en la materia encuadran bien con la caracterización de la archivística clásica. En cuanto a la práctica de la disciplina, ya desde entonces es claro que el AGN ha sido la institución rectora del desarrollo archivístico en México. De hecho, según se aprecia en su Reglamento vigente en la época (Secretaría de Gobernación, 1946), el archivo es considerado principalmente como "histórico", sin dejar de atender las cuestiones administrativas. Más aún, claramente se señala que para los puestos directivos de carácter técnico se deben de tener estudios en historia, paleografía o de archivística. Todo lo anterior se refleja en la organización del archivo, "[...] distribuido en las siguientes secciones: A.- De Paleografía. B.- De Investigaciones Históricas. C.- Administrativa. E.- De Biblioteca y Publicaciones" (Secretaría de Gobernación, 1946: 2).

En otro orden de cosas, con la revisión de la vida y obra de Razo Zaragoza es posible advertir sus aportaciones para los inicios de la archivística profesional en Jalisco. Son tres las áreas en las cuales consideramos se aprecia su huella de manera directa, todas ellas sustentadas en el hecho de que durante mucho tiempo fue el único profesional con formación de archivista en el estado de Jalisco, quizá el primero. Aún hoy desconocemos si hay archivistas profesionales en puestos de toma de decisiones. De hecho, en la legislación estatal que rige los diferentes archivos de la entidad esta profesión no es considerada como obligatoria para alcanzar una dirección o subdirección (Congreso del Estado de Jalisco, 1998). En cambio, para el AIPEJ se establece como requisito legal que los titulares deben ser abogados o historiadores, relegando a los archivistas a puestos de segundo nivel con carácter operativo (Gobierno del Estado de Jalisco. Poder Ejecutivo. Secretaría General de Gobierno, 1996). 
En cuanto a la primera de las áreas, se trata de los archivos institucionales. En el Municipal de Guadalajara Razo Zaragoza conformó una estructura que, de acuerdo a su época, resultaba avanzada puesto que en ese momento un archivo solía no tener ni personal ni presupuesto propio. En el del IJAH, dio la guía para su organización de acuerdo con las características y el tamaño de la institución, lo mismo sucedió con el Archivo de La Barca, Jalisco. La segunda área se refiere a los archivos históricos, donde no estuvo en puestos de toma de decisiones pero en donde desarrolló su labor como paleógrafo. Aquí contribuyó a la elaboración de índices, acción sobre la cual se sustenta cualquier principio de organización posterior. De igual manera, su archivo personal que deviene público demuestra su capacidad para la organización documental. La tercera área es la docencia, en ésta volcó no sólo la preparación que había obtenido tanto en la ENAH como en la UNAM, sino también la experiencia que adquirió a lo largo de los años en su trabajo como archivista, principalmente paleógrafo. Como se señaló en el cuerpo del artículo, varios de sus alumnos incidieron en la formación del Archivo Histórico de Jalisco, mientras que otros se han desarrollado como historiadores profesionales.

Cuando se observa la labor de Razo Zaragoza en el marco de la teoría archivística y del desarrollo de los archivos en México, se puede apreciar que, como profesional, fue un archivista clásico. Muestra de ello fue su preocupación por la organización y cuidado de los archivos históricos, así como la elaboración de guías e índices para estas instituciones, con la finalidad de facilitar el trabajo historiográfico. En ese sentido, sus aportes no se registran en la discusión teórica de la disciplina, sino más bien en el ejercicio empírico de ella. No obstante, no se puede decir que nuestro biografiado haya sido "ateórico", sino por el contrario, debió de reconocer y apoyarse en la teoría archivística. De otra forma no es posible explicarse las propuestas para la organización de los archivos con los que estuvo involucrado, ni el orden y el cuidado de la documentación que tuvo a su cargo. Por todo lo anterior, consideramos que la actividad de Razo Zaragoza contribuyó a la formación de la archivística profesional en el estado de Jalisco.

\section{Agradecimientos}

Se agradece aquí el apoyo brindado por la Biblioteca Pública Municipal "Jaime de Anasegasti" de Tonalá, Jalisco, al ofrecer las condiciones materiales para la elaboración de este trabajo. De igual manera, al Instituto Jalisciense de Antropología e Historia, por el acceso a su archivo y las facilidades para implementar el proyecto de investigación. La Universidad de 
Guadalajara, a través del Centro Universitario de Ciencias Sociales y Humanidades, financió parcialmente este proyecto mediante el programa 7.1 (Apoyo a la investigación). De igual forma, se reconocen los comentarios y sugerencias de los dictaminadores anónimos.

\section{BibliografíA}

Ayuntamiento de Guadalajara (1955), "Presupuesto de egresos", en Gaceta municipal. Publicación mensual del H. Ayuntamiento de Guadalajara, vol. 23, núm. 1, enero, pp. 41-51.

Congreso del Estado de Jalisco (1998), "Decreto núm. 17032. Ley que regula la administración de documentos públicos e históricos del estado de Jalisco", publicada en Periódico Oficial El Estado de Jalisco, 8 de enero de 1998.

Fernández Aceves, María Teresa (2008), "Los retos de la organización y transparencia en el Archivo Histórico de Jalisco", en Desacatos. Revista de antropología social, vol. 26, enero-abril, pp. 43-58.

Galván Ruiz, Cándido (1988), "Instituto Jalisciense de Antropología e Historia”, en C. García Mora y M. Mejía Sánchez (coords.), La antropología en México: panorama histórico. Las instituciones, México: Instituto Nacional de Antropología e Historia, pp. 180-192.

Giraldo Lopera, Marta Lucía (2009), "Archivística: fundamentación teórica y tradición formativa", en Revista Interamericana de Bibliotecología, vol. 32, núm. 1, enero-junio, pp. 31-45.

Gobierno de Jalisco (2011), Jaliscienses distinguidos. Páez Brotchie Luis. Disponible en: http://app.jalisco.gob.mx/jalisco/jaliscienses/html /paezBrotchie.html [Fecha de consulta: 27 de abril de 2011].

Gobierno del Estado de Jalisco. Poder Ejecutivo. Secretaría General de Gobierno (1996), Reglamento Interior de la Dirección del Archivo de Instrumentos Públicos de la Secretaría General de Gobierno del Ejecutivo Estatal, publicado en Periódico Oficial El Estado de Jalisco, 12 de septiembre de 1996, t. CCCXXIII, núm. 40, pp. 480485.

Gómez Gastélum, Luis; Ramírez Munguía, Cristina y Guzmán Becerra, Mayela (2009), "El archivo histórico del IJAH, fuente para la historia cultural del occidente de México", en IX Jornadas archivísticas de la RENAIES, Memoria electrónica, Guadalajara: Universidad de Guadalajara.

González Claverán, Virginia; Dorantes González, Alma y Olveda, Jaime (1975), "Problemas de la investigación histórica en Jalisco", en XIII Mesa Redonda. Balance y perspectiva de la antropología de Mesoamérica y del Norte de México, México: Sociedad Mexicana de Antropología, pp. 211-219. 
Matute Remus, Jorge (1954), "Informe rendido por el C. Presidente Municipal Ing. Jorge Matute Remus, al cumplir el primer año de su ejercicio", en Gaceta municipal. Publicación mensual del H. Ayuntamiento de Guadalajara, vol. 22, núm. 1, enero, pp. 3-27.

Montilla Peña, Leomar José y Mena Mujica, Mayra M. (2013), "Estado de desarrollo de la archivística clásica hasta los años 30 del siglo XX: Tres manuales archivísticos de trascendencia universal", en Biblios, vol. 52, pp. 43-58. Disponible en: http://biblios.pitt. edu/ojs/index.php/biblios/article/view/122 [Fecha de consulta: 7 de febrero de 2014].

Muriá, José María (1989), “Comentario”, en R. Ávila Palafox (comp.), El occidente de México. Arqueología, historia, antropología, Guadalajara: Universidad de Guadalajara, pp. 67-74.

Olveda, Jaime (2008), "La historiografía independentista del noroccidente de México", en Estudios jaliscienses, vol. 74, noviembre, pp. 5-20.

Ramírez Aceves, Merizanda M. C.; Sánchez Espinoza, Ariel; Birrichaga Gardida, Diana y Beltrán Cabrera, Luz del Carmen (2011), "El devenir histórico de la cultura archivística en México", en Información, cultura y sociedad, vol. 24, pp. 39-68.

Razo Zaragoza, José Luis (1968), "Guía paleográfica”, en A. Tello, Crónica miscelánea de la Sancta Provincia de Xalisco, Guadalajara: Gobierno del Estado de Jalisco, Universidad de Guadalajara, Instituto Jalisciense de Antropología e Historia, Instituto Nacional de Antropología e Historia, pp. xciii-xcvii.

_ (1970), "Normas paleográficas", en Actas de Cabildos de la ciudad de Guadalajara. Volumen primero, 1607-1635, Guadalajara: Ayuntamiento Constitucional de Guadalajara e Instituto Jalisciense de Antropología e Historia, pp. xvii-xxii.

—_ (1981), "Archivo histórico de la Universidad de Guadalajara. Un estudio. Un proyecto. Una realidad”, en Revista Eco, vol. 2, núm. 8, diciembre, pp. 15-18.

- (1991a), Ego Sum. Currículum vitae, bibliografía, hemerografía, comentarios, testimonios 1931-1990, La Barca, Jalisco: Ediciones Ateneo Regional de La Barca.

(1991b), Guía del archivo documental e histórico de La Barca, Guadalajara: Fundación Hermanos Razo Zaragoza. (2004), Índice documental de la propiedad raiz en el Nuevo Reino de Galicia, Guadalajara: Instituto Jalisciense de Antropología e Historia.

Rodríguez Gallardo, José Adolfo (2003), Formación bumanística del bibliotecólogo: hacia su recuperación, México: UNAM.

Secretaría de Gobernación (1946), "Reglamento del Archivo General de la Nación”, en Diario Oficial. Órgano del Gobierno Constitucional de los Estados Unidos Mexicanos. 
Topete Rodríguez, Alma Elizabeth y Pedraza Rodríguez, Carmen (2007), Fondo Razo Zaragoza, Guadalajara: Gobierno del Estado de Jalisco.

Torres Verdín, Mario Humberto (1990), "La Dirección del Archivo de Instrumentos Públicos del Estado de Jalisco", en Podium notarial, vol. 2. Disponible en: http://www.revistanotarios.com/?q= node/53 [Fecha de consulta: 27 de abril de 2011].

Vivas Moreno, Agustín (2004), "El tiempo de la archivística: un estudio de sus espacios de racionalidad histórica", en Ciência da Informação, vol. 33, núm. 3, septiembre-diciembre, pp. 76-96. Disponible en: http://www.scielo.br/pdf/ci/v33n3/a10v33n3.pdf [Fecha de consulta: 7 de febrero de 2014].

\section{Documento DE ARCHIVO}

AIJAH (Archivo del Instituto Jaliciense de Antropología e Historia), Fondo Razo Zaragoza, caja 12, carpeta 38. 